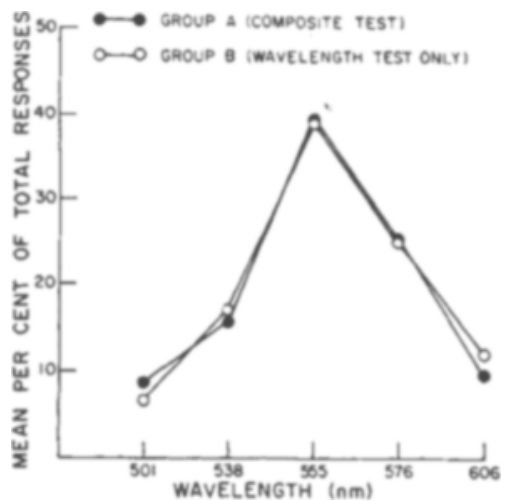

Fig. 2. Mean relative wavelength generalization gradients of Groups $A$ and $B$.

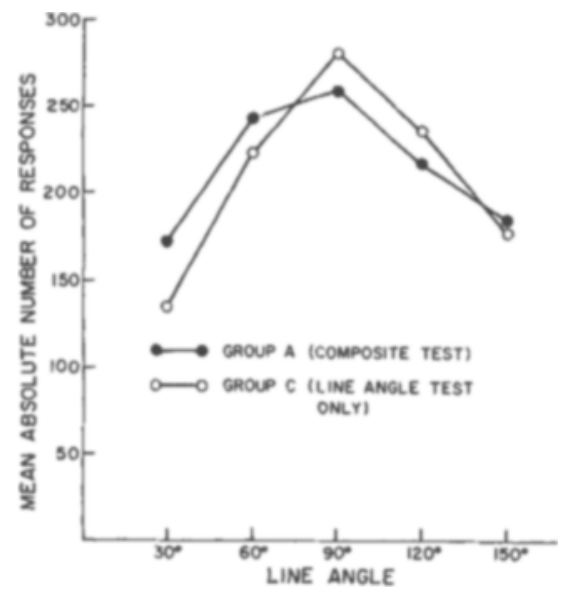

Fig. 3. Mean absolute angularity generalizationgradients of Groups A and C.

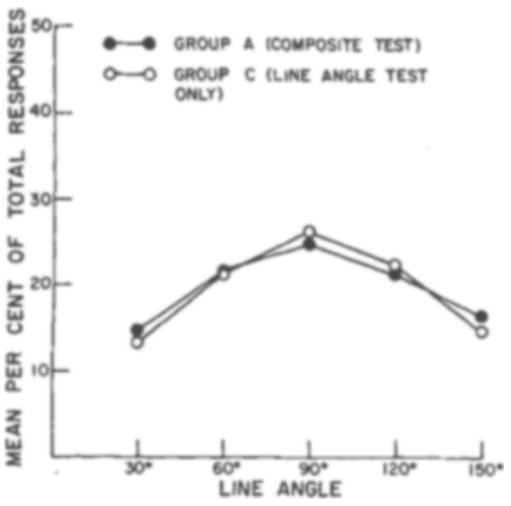

Fig. 4. Mean relative angularity generalization gradients of Groups $A$ and $C$.

Neither group nor interaction effects approach statistical significance, however [group, $\mathrm{F}<1$; interaction, $\mathrm{F}(4,112)=1.7$, $\mathrm{p}>.10]$. The mean relative angularity gradients of Groups $A$ and $C$, shown in Fig. 4, are virtually identical, and again statistical analysis reveals no significant group or Group by Stimuli interaction effect $(\mathrm{F}<1)$.

This experiment agrees with the earlier ones performed with pigeons in finding that, following variable-interval training, the generalization gradient obtained within-Ss in extinction is substantially immune from successive contextual effects. This is the case whether the gradient is plotted in absolute or in relative terms. There is a slight suggestion from the data of the present study that the alternated presence of wavelength stimuli in the test may flatten the angularity gradient, but the effect falls far short of significance despite the fact that larger groups were used in this study than is typical of operant stimulus control studies. The failure to reject the null hypothesis cannot be taken to mean that there is absolutely no effect of having two stimulus dimensions present during generalization testing, but it can certainly be said that any effect obtained is likely to be of very limited magnitude and thus of no practical consequence. In view of the consistent demonstration of the insensitivity of the generalization gradient (yielded by these procedures) to successive contextual effects, the increased efficiency afforded by within-Ss designs in the study of bidimensional stimulus generalization adequately justifies their use.

\section{REFERENCES}

BUTTER, C. M. Stimulus generalization along one and two dimensions in pigeons. Journal of Experimental Psychology, 1963, 65, 339-346. CROSS, D. V. Metric properties of multidimensional stimulus generalization. In D. I.
Mostofsky (Ed.), Stimulus generalization. Stanford, Calif.: Stanford University Press, 1965. Pp. 72-93.

FRIEDMAN, H. Wavelength generalization as a function of spacing of test stimuli. Journal of Experimental Psychology, 1963, 65, 334-338.

HISS, R. H., \& THOMAS, D. R. Stimulus generalization as a function of testing procedure and response measure. Journal of Experimental Psychology, 1963, 65, 587-592.

KALISH, H. I., \& HABER, A. Generalization: I. Generalization gradients from single and multiple stimulus points. II. Generalization of inhibition. Journal of Experimental Psychology, 1963, 65, 176-181.

THOMAS, D. R., \& BARKER, E. G. The effects of extinction and "central tendency" on stimulus generalization in pigeons. Psychonomic Science, 1964, 1, 119-120.

THOMAS, D. R., \& HISS, R. H. A test of the "Units Hypothesis" employing wave-length generalization in human subjects. Journal of Experimental Psychology, 1963, 65, 59-62.

THOMAS, D. R., \& JONES, C. G. Stimulus generalization as a function of the frame of reference. Journal of Experimental Psychology, 1962,64, 77-80.

THOMAS, D. R., F'REEMAN, F., SVINICKI, J.G. BURR, D. E. S., \& LYONS, J. The effects of extra-dimensional training on stimulus generalization. Journal of Experimental Psy chology, in press.

\section{NOTES}

1. This research was supported by Research Grant HD-03486 and Training Grant MH-10427 under the direction of the second author. D. E. Scott Burr and Robert Hintz aided in the collection of the data.

2. Thomas, D. R., Burr, D. E. S., \& Svinicki, M. $D$. Evidence for a positive relationship between degree of control acquired by two dimensions of a complex stimulus. Submitted to Nature, 1969.

\title{
Chronic effects of social stimuli on adrenocortical function in male mice'
}

\section{JOHN ARCHER, ${ }^{2}$ University of Bristol, England}

Recent work showed that when previously isolated male mice are housed in proximity with one another, their adrenals become heavier than those of mice remaining in isolation. The present experiment revealed that this adrenal hypertrophy no longer occurred when the differential housing period was longer, i.e., 9 weeks instead of 2 weeks. These results suggest that the adrenal response was associated with the reaction of strange animals to one another, rather than the chronic effects of social stimulation.
Experiments carried out on rodents reveal that isolation and group housing exert contrasting effects on adrenocortical function. The precise nature of these effects seems to depend on the experimental procedure used: Preexperimental isolation and the occurrence of aggressive behavior are associated with higher levels of adrenal function in the grouped animals ("social stress"), and preexperimental grouping and the absence of aggression are often associated with smaller differences in the opposite direction ("isolation stress"). The literature on which the above conclusions are based will be considered more fully in a review article, but typical examples of social stress are to be found in the work of 
Table 1

Body weights and adrenal weights of male mice after 9 weeks in proximity with other males or after the same period of time in social isolation.

\begin{tabular}{lcccccc} 
& \multicolumn{3}{c}{ Proximity } & without Contact & \multicolumn{3}{c}{ Social Isolation } \\
& $\overline{\mathrm{X}}$ & $\mathrm{S}$ & $\mathrm{N}$ & $\overline{\mathrm{X}}$ & $\mathrm{S}$ & $\mathrm{N}$ \\
\hline $\begin{array}{l}\text { Relative adrenal weights } \\
\text { (mg/100 g body weight) }\end{array}$ & 11.3 & 1.42 & 16 & 11.8 & 2.62 & 16 \\
$\begin{array}{l}\text { Absolute adrenal weights } \\
\text { (mg) }\end{array}$ & 3.6 & 0.52 & 16 & 3.5 & 0.62 & 16 \\
$\begin{array}{l}\text { Body weights } \\
\text { (g) }\end{array}$ & 31.8 & 2.87 & 16 & 30.0 & 3.24 & 16 \\
\hline
\end{tabular}

Christian (1955a, b), Vandenberg (1960), and Louch \& Higginbotham (1967); isolation stress has been reported by Hatch et al (1963), Geller et al (1965), and others.

Although aggressive behavior among the grouped animals seems to be the primary determinant of social stress (Bronson \& Eleftheriou 1964, 1965a, b), recent work has shown that the adrenal cortex is sensitive to other social stimuli occurring in grouped rodents.

The present author (Archer, 1969) has shown that housing previously isolated male mice in proximity with other males (but without tactile contact) for 2 weeks elicits increased relative adrenal weights and decreased ascorbic acid levels compared with mice remaining in social isolation. A similar trend in relative adrenal weights was found when this experiment was repeated using a 12-day period and a different cage size. ${ }^{3}$

The present study investigates whether adrenal hypertrophy in response to the presence of conspecifics is accentuated by using a longer experimental duration, i.e., 9 weeks instead of 2 weeks. Adrenal ascorbic acid levels were not used, as this measure represents shorter-term fluctuations in adrenocortical function, rather than the cumulative changes in secretory activity reflected by adrenal weights.

\section{METHOD}

Thirty-six male SASTO mice (a randombred closed colony, held by Scientific Animal Service, Elstree, since 1954), aged 6 to 8 weeks, were isolated in cages measuring $6 \times 12 \times 6$ in. for 3 weeks, after which they were assigned to one of two conditions. The experimental condition involved housing the animals in a large cage $(12 \times 12 \times 6$ in. $)$, divided into nine compartments separated by double wire-mesh partitions. The control condition involved housing the male mice in metal-sided cages measuring $4 \times 4 \times 4$ in., i.e., with the same floor space as each compartment of the cage used for housing the experimental animals.

The experimental period lasted 9 weeks, and at the end of this time all mice were sacrificed and their adrenal weights and body weights recorded.

Equal numbers of control and experimental animals were housed at the same time and the experiment was carried out in two parts, using nine experimental and nine control animals for each part. ${ }^{4}$

\section{RESULTS}

The means and standard deviations for the body weights, absolute adrenal weights and relative adrenal weights are shown in Table 1 . In the case of both absolute and relative adrenal weights, the variance for the control values is greater than that for the experimentals. This difference is not statistically significant with regard to absolute adrenal weights $\left(F=1.39 ; f_{1}=15\right.$, $f_{2}=15 ; p>0.1$ ), but it is in the case of the relative adrenal weights $\left(F=2.84 ; f_{1}=15\right.$, $\left.f_{2}=15 ; p=0.05\right)$. The means of the relative adrenal weights for the two conditions are not significantly different $(U=108$; $\left.n_{1}=16, n_{2}=16 ; p>0.1\right)$, nor are the means of the absolute adrenal weights $(t<0.1 ; d f=30, p>0.1)$.

\section{DISCUSSION}

The results of this experiment indicate that no adrenal hypertrophy occurs in response to the presence of conspecifics if a 9-week experimental duration is used. Therefore it is likely that the adrenocortical activation found by the present author in the shorter-term study (Archer, 1969) was associated with the response of previously isolated animals to the presence of one another, rather than a long-term tonic adjustment of the rate of secretory activity to the increased level of social stimulation.

Another important aspect of the adrenal weight data is the smaller variance of the values for the experimental animals. Differences in the variance of adrenal activity in response to the social environment is a subject which has of ten been neglected in group density studies, although notable exceptions are the discussions of Welch \& Klopfer (1961) and Welch (1964). When considering the effects of grouping on physiological activity, Welch (1964) postulated that there are two opposing trends-one towards homogeneity and the other towards diversity. The latter arises from the fact that there is a gradient of social effects associated with the animals' dominance relations, and the former from their sharing a common social environment. The reason for the decreased variance in the present case may be associated with all the experimental animals being exposed to a similar social environment in a situation where no dominance relations could be established. Hence the social stimuli tending to cause diversity of physiological response are removed while those causing homogeneity still remain. A similar, more pronounced, trend towards homogeneity of variance was found in an experiment concerning male odors and adrenal function (Archer, in press): Isolated male mice exposed to the same group odors showed significantly decreased variance compared with mice not receiving group odors.

\section{REFERENCES}

ARCHER, J. E. Effects of social stimuli on the adrenal cortex in male mice. Psychonomic Science, 1969, 14, 17-18

ARCHER, J. E. Adrenocortical responses to olfactory social stimuli in male mice. Journal of Mammalogy, in press.

BRONSON, F. H. \& ELEFTHERIOU, B. E. Chronic physiological effects of fighting in mice. General \& Comparative Endocrinology, $1964,4,9-14$.

BRONSON, F. H., \& ELEFTHERIOU, B. E. Adrenal responses to fighting in mice: Separation of phy sical and psychological causes. Science, 1965a, 147, 627-628.

BRONSON, F. H. \& ELEFTHERIOU, B. E. Behavioral, pituitary and adrenal correlates of controlled fighting in mice. Physiological Zoology, 1965b, 38, 406-411.

CHRISTIAN, J. J. Effects of population size on the adrenal glands and reproductive organs of male mice in populations of fixed size American Journal of Physiology, 1955a, 182 , 292-300.

CHRISTIAN, J. J. Effects of population size on the weights of the reproductive organs of white mice. American Journal of Physiology, 1955b $181,477-480$.

GELLER, E., YUWILER, A., \& ZOLMAN, J. F. Effects of environmental complexity on constituents of brain and liver. Joumal of Neurochemistry, 1965, 12, 949-955.

HATCH, A., BALAZS, T., WIBERG, G. S., \& GRICE, H. C. Long-term isolation stress in rats. Science, 1963, 142, 507 .

LOUCH, C. D., \& HigGinbothaM, M. The relation between social rank and plasma corticosterone levels in mice. General \& Comparative Endocrinology, 1967, 8, 441-444.

VANDENBERG, J. G. Eosinophil response to aggressive behaviour in CFW albino mice. Animal Behaviour, 1960, 8, 13-18.

WELCH, B. L. Psychophysical response to the mean level of environmental stimulation: A theory of environmental integration. In D. M. Rioch (Ed.), Medical aspects of stress in the military climate. Washington, D.C.: U.S. Government Printing Office, 1964. Pp. 39-99. WELCH, B. L., \& KLOPFER, P. H. Endocrine variability as a factor in the regulation of population density. American Naturalist, 1961, 95, 256-260.

\section{NOTES}

1. I thank S.R.C. and the Wellcome Trust for financial assistance, and Dr. J.D. Goss-Custard for critical comments and discussion. Special thanks are also due to Dr. B. L. Welch (University of Tennessee) for commenting on an earlier draft of this paper.

2. Present address: Department of Psychology, University of Nottingham, England.

3. Archer, J. Unpublished data.

4. Reduced to 16 per condition owing to errors in dissection. 